\title{
Different Intraoperative Ventilatory Strategies for Prevention of Pulmonary Atelectasis in Obese Patients Undergoing Non-Bariatric Surgeries; Randomized Controlled Trial Mohamed Ezzat Abd El-Fattah" ${ }^{\mathbf{1}}$, Doaa Mohamed Faried ${ }^{1}$, Essam Fathi Abd-El Galel ${ }^{1}$, Ayat Ahmed Amer ${ }^{1}$, Ahmed Abd El-Aziz El-Sammak ${ }^{2}$ \\ Departments of ${ }^{1}$ Anesthesia and Surgical Intensive Care and ${ }^{2}$ Radiodiagnosis, Faculty of Medicine, Zagazig University, Egypt. \\ *Corresponding Author: Mohamed Ezzat Abd El-Fattah, Mobile: (+20) 01013719345, mohammedezzat2002@gmail.com
}

\begin{abstract}
Background: Upper abdominal surgeries have been reported to be associated with an increased incidence of postoperative atelectasis. Preventing atelectasis is important for all patients but is more important when caring for obese patients.

Objectives: To determine which of the following ventilatory strategies is better in prevention of pulmonary atelectasis in obese patients undergoing non-bariatric surgery: Volume control ventilation "VC", Pressure control Ventilation "PC", Volume control ventilation + Positive End Expiratory Pressure "PEEP", Volume control ventilation + Positive End Expiratory Pressure "PEEP" + lung recruitment maneuver.

Patients and methods: A randomized-controlled trial study was carried out in the operating room (OR) in Zagazig University Hospital including 92 patients. Patients were randomly allocated into four groups. G1: Volume control ventilation "VC", G2: Pressure control Ventilation "PC", G3: Volume control ventilation + Positive End Expiratory Pressure "PEEP", G4: as in G3 + lung recruitment maneuver.

Results: There was significant difference between the studied groups as regards $\mathrm{PaO}_{2} / \mathrm{FiO}_{2}$ ratio as the $4^{\text {th }}$ group was highly significant. There was also significant difference between the studied groups as regards atelectasis score with the least atelectasis score in group 4. There was a significant difference in group 4 than the other groups as regards length of stay in PACU, and need for 100\% Fio2 in PACU. Finally, there was a significant difference between the studied groups as regards postoperative pulmonary complications with the $4^{\text {th }}$ group has the least postoperative complication.

Conclusion: Our results suggest that volume control ventilation + Positive End Expiratory Pressure "PEEP" + lung recruitment maneuver had beneficial effects on oxygenation continued into the early recovery period and decrease pulmonary complications in the early post-operative period in obese patients undergoing non-bariatric upper abdominal surgeries.
\end{abstract}

Keywords: Atelectasis, Obese, Ventilatory Strategies, Bariatric.

\section{INTRODUCTION}

Obesity is a major anesthetic challenge in the operation room. The number of obese patients undergoing surgery, either bariatric or non-bariatric is steadily increasing (1). Atelectasis is one of the aesthetic enemies even in non-obese patients as it leads to reduction in both ventilation-perfusion ratio and pulmonary compliance ${ }^{(2)}$. The altered respiratory mechanics in obese patients tend to further exaggerate impairment of gas exchange. It has been demonstrated that in anesthetized patients, arterial partial pressure of oxygen $\left(\mathrm{PaO}_{2}\right)$ is inversely related to body mass index $(\mathrm{BMI})^{(3)}$.

The non-desirable complications such as hypoxia and atelectasis may extend to the postoperative period and this necessitates some interventions that vary from supplemental oxygen, chest physiotherapy, noninvasive ventilation up to re-intubation and ICU admission with increasing morbidity and mortality ${ }^{(4)}$.

Obesity is considered a major challenge for the anesthesiologist regarding both airway and pulmonary mechanics. Airway changes due to obesity are the first and foremost concern of the anesthesiologist ${ }^{(5)}$.

Obese patients have an increased neck circumference and dimensions, increased soft tissue surrounding the upper airway and lack of anterior and lateral bony support of the nasopharynx, oropharynx, and hypopharynx. These factors exacerbate airway obstruction. Especially in anesthetized patients during induction and emergence of anesthesia. Any of these factors alone or in combination can make intubation and mask ventilation of obese patients extremely challenging.

The obese patient is always considered to have a difficult airway. Precautions are taken to place the patient in a "sniffing" position, also known as head elevated laryngoscopy position (HELP) $^{(6)}$, which places the sternal notch and external auditory meatus in an imaginary horizontal line facilitating intubation. In addition to using this position, the anesthesiologist uses multiple other strategies for airway management based on the American Society of Anesthesiologists' Difficult Airway Algorithm ${ }^{(7)}$. 
The pulmonary mechanics especially function residual capacity (FRC) and expiratory reserve volume (ERV) are so important for the anesthesiologist as BMI has an inverse relation to both of them, which leads to early airway closure with gas trapping causing ventilation-perfusion mismatching and subsequent hypoxia. Obesity also leads to generation of intrinsic positive end-expiratory pressure, increased work of breathing, and decreased chest wall compliance. All these changes are further exaggerated in the supine position ${ }^{(8)}$. Several ventilatory strategies aiming to optimize gas-exchange and pulmonary mechanics and to minimize the risk of postoperative respiratory complications have been tested, for example, various ventilation modes, positive end-expiratory pressure, or recruitment maneuvers (RM), which is the application of a sustained increase in positive pressure to the airway in order to reopen collapsed alveoli. However, we are still searching for the ideal ventilation strategy which hasn't yet been established.

The aim of this work was to determine which of these ventilatory strategies is better in prevention of pulmonary atelectasis in obese patients undergoing non-bariatric surgery: Volume control ventilation (VC), pressure control ventilation (PC), volume control ventilation + positive end-expiratory pressure or volume control ventilation + positive end-expiratory pressure + lung recruitment maneuver

\section{PATIENT AND METHOD}

The study was conducted over 92 patients who met the inclusion criteria. This was done under supervision of Anesthesia and Surgical Intensive Care Department, Faculty of Medicine, Zagazig University during the period from January 2018 to January 2020.

\section{Ethical approval:}

After approval of Local Ethics Committee of Zagazig University, this prospective randomizedcontrolled trial was carried out in the Operating Room (OR) in Zagazig University Hospital. A written consent was obtained from each participant.

\section{Inclusion criteria:}

- Adult patients from 20 to 50 years old of both sex

- Body mass index 30-40 $\mathrm{kg} \backslash \mathrm{m}^{2}$. Patients undergoing upper abdominal surgery.

-

\section{Exclusion criteria:}

- Age below 20 years and above 50 years.

- COPD and asthmatic patients.

- Hepatic patients with moderate to tense ascites. Pregnancy and hemodynamic instability.

- ASA: III and IV.

- Patient refusal.

\section{Tools of data collection:}

From each patient the following data were collected: Name, age, BMI, sex, type of surgery, date of admission to hospital and history of medical diseases.

\section{Methods:}

CT chest was done at the night before surgery; patients were fasted for at least 8 hours before the induction of anesthesia, the anesthetist who was collecting data was blind about the study.

Patients were premedicated with $0.5 \mathrm{mg}$ atropine IV, metoclopramide $10 \mathrm{mg}$ IV, ranitidine $50 \mathrm{mg}$ IV slowly and $3 \mathrm{mg}$ midazolam IV before induction of anesthesia. Arterial line was inserted for all patients for invasive blood pressure monitoring and arterial blood gases sampling. Patients were connected to monitor and baseline parameters were recorded including: Mean arterial pressure (MAP), heart rate (HR), systolic blood pressure (SBP), diastolic blood pressure (DBP) and respiratory rate (RR). Induction of anesthesia was achieved by administration of oxygen by facemask $\left(100 \% 0_{2}\right)$ for $3-5 \mathrm{~min}$. followed by 2 $\mathrm{mg} \mid \mathrm{kg}$ propfol $1 \%, 1 \mathrm{ug} \mathrm{kg}$ fentanyl and $0.15 \mathrm{mg} \mathrm{kg}$ cistracurium to facilitate tracheal intubation. Anesthesia was maintained using isoflurane and cistracurium in all patients. Ventilation was adjusted according to capnography to maintain end-tidal carbon dioxide between 30-35 mmHg. Patients were randomized into 4 groups by a computer-generated random numbering system with the use of sealed opaque envelope.

Datexohmeda anesthesia machine was used. 1st group is volume control group; ventilation with a tidal volume of $7 \mathrm{ml} / \mathrm{kg}$ ideal body weight, $2^{\text {nd }}$ group is pressure control, and the pressure was adjusted to achieve tidal volume of $7 \mathrm{mllkg}$ of ideal body weight. $3^{\text {rd }}$ group is volume control ventilation with positive end-expiratory pressure ventilation with a tidal volume of $7 \mathrm{mllkg}$ ideal body weight and positive endexpiratory pressure of $5 \mathrm{cmH}_{2} \mathrm{O} .4^{\text {th }}$ group is volume control + positive end-expiratory pressure + recruitment maneuver ventilation with a tidal volume of $7 \mathrm{mllkg}$ ideal body weight and positive endexpiratory pressure of $5 \mathrm{cmH}_{2} \mathrm{O}+$ recruitment maneuver, which were performed by sudden increase in positive end-expiratory pressure from $5 \mathrm{cmH}_{2} \mathrm{O}$ to $40 \mathrm{cmH}_{2} \mathrm{O}$ for 7-8 seconds. The recruitment maneuver was performed immediately after intubation and just before extubation; positive end-expiratory pressure of $5 \mathrm{cmH}_{2} \mathrm{O}$ was applied through all the surgery.

Initial CT chest was done overnight of surgery and follow up CT chest was done just after discharge from post-anesthesia care unit (PACU). Crystalloid solution at a rate of $10 \mathrm{mllkg}$ was administered to all patients starting immediately after insertion of IV cannula until patient positioned followed by $10 \mathrm{ml} \mathrm{kg} \mathrm{kh}$ until the end 
of surgery with replacement of blood loss if present. Intraoperative hypotension (MAP $<20 \%$ of baseline) was treated with a bolus of normal saline $0.9 \% 250 \mathrm{ml}$ andlor incremental doses of $6 \mathrm{mg}$ IV ephedrine. At the end of surgery isoflurane was discontinued and the muscle relaxant was reversed by neostigmine 0.05 $\mathrm{mg} \backslash \mathrm{kg}$ and $0.02 \mathrm{mg} \backslash \mathrm{kg}$ atropine sulfate. Tracheal extubation was performed in semisiting position after reaching satisfactory criteria for extubation which were as follow:

- Intact neurological status (fully awake, alert and head left).

- Haemodynamic stability.

- Full reversal of neuro-muscular blocking drugs.

- Respiratory rate $>10$ and $<30$ breathlmin.

After extubation, the patient was kept at a head-up tilt of $30^{\circ}-45^{\circ}$, with continuous oxygen supplementation by facemask oxygen $6 \mathrm{LImin}$ and acceptable pain control by $1 \mathrm{gm}$ paracetamol IV with supplemental pethidine according to visual analogue score to prevent post-extubation hypoxia. In the PACU, all patients were evaluated by Aldret score after 30 minute and 1 hour from post-anesthesia care unit (PACU) admission. Oxygen saturation, arterial blood gases were measured to determine if hypoxemia is present or corrected and hypercapnia is present or corrected. If hypoxemia is still present: high flow oxygen is applied by Non Rebreathing Mask (NRM) 5 LImin and chest wall percussion (chest physiotherapy)

If hypercapnia was still present, suction of patient secretion, chest wall percussion and tries to awaken the patient if still sleepy. If hypoxaemia and hypercapnia were still present regardless the previous measures patient was transferred to ICU.

\section{Measurements:}

$\mathrm{HR}$, MAP and $\mathrm{O} 2$ sat, were measured at the following times:

- TB: before induction.

- T1: immediately after induction of anesthesia.

- T2; immediately after skin incision.

- T3: 30 min after skin incision.

- T4: 1 hour after skin incision.
- T5: immediately after post-anesthesia care unit (PACU) admission.

- T6:30 min after admission to PACU.

- T7: immediately before discharge from PACU.

Partial pressure of oxygen $\left(\mathrm{PaO}_{2}\right)$, partial pressure of oxygen $\left(\mathrm{PaO}_{2}\right)$ /fraction inspired oxygen saturation $\left(\mathrm{FiO}_{2}\right)$ ratio, and partial pressure of carbon dioxide $\left(\mathrm{PaCO}_{2}\right)$ were measured by arterial blood gases at the following times:

- TB: before induction.

- T1: 30 minutes after skin incision.

- T2: immediately after PACU admission.

- T3: 30 minutes after PACU admission.

Atelectasis score: It was measured by radiologist by comparison of both initial CT-chest and follow-up CT chest.

\section{Sample size calculation:}

It was calculated according to arterial partial pressure of oxygen/fraction inspired oxygen $\left(\mathrm{PaO}_{2} / \mathrm{FiO}_{2}\right.$ ratio) in previous study ${ }^{(10)}$. It was calculated by Open-Epi program to be 92 patients ( 23 patients in each group) with CI $95 \%$ and power of the test $80 \%$.

\section{Statistical analysis}

Data were collected (throughout history, basic clinical examination, laboratory investigations and outcome measures) coded, entered and analyzed using Microsoft Excel software. Data were then imported into Statistical Package for the Social Sciences (SPSS version 20.0) (Statistical Package for the Social Sciences) software for analysis. According to the type of data, qualitative data were represented as number and percentage, and quantitative data were represented by mean $\pm \mathrm{SD}$.

Difference and association of qualitative variable were tested by Chi square test $\left(\mathrm{X}^{2}\right)$. Differences between quantitative independent groups was tested by $\mathrm{t}$ test. $\mathrm{P}$ value was set at $\leq 0.05$ for significant results $\&<0.001$ for high significant results. 


\section{RESULTS}

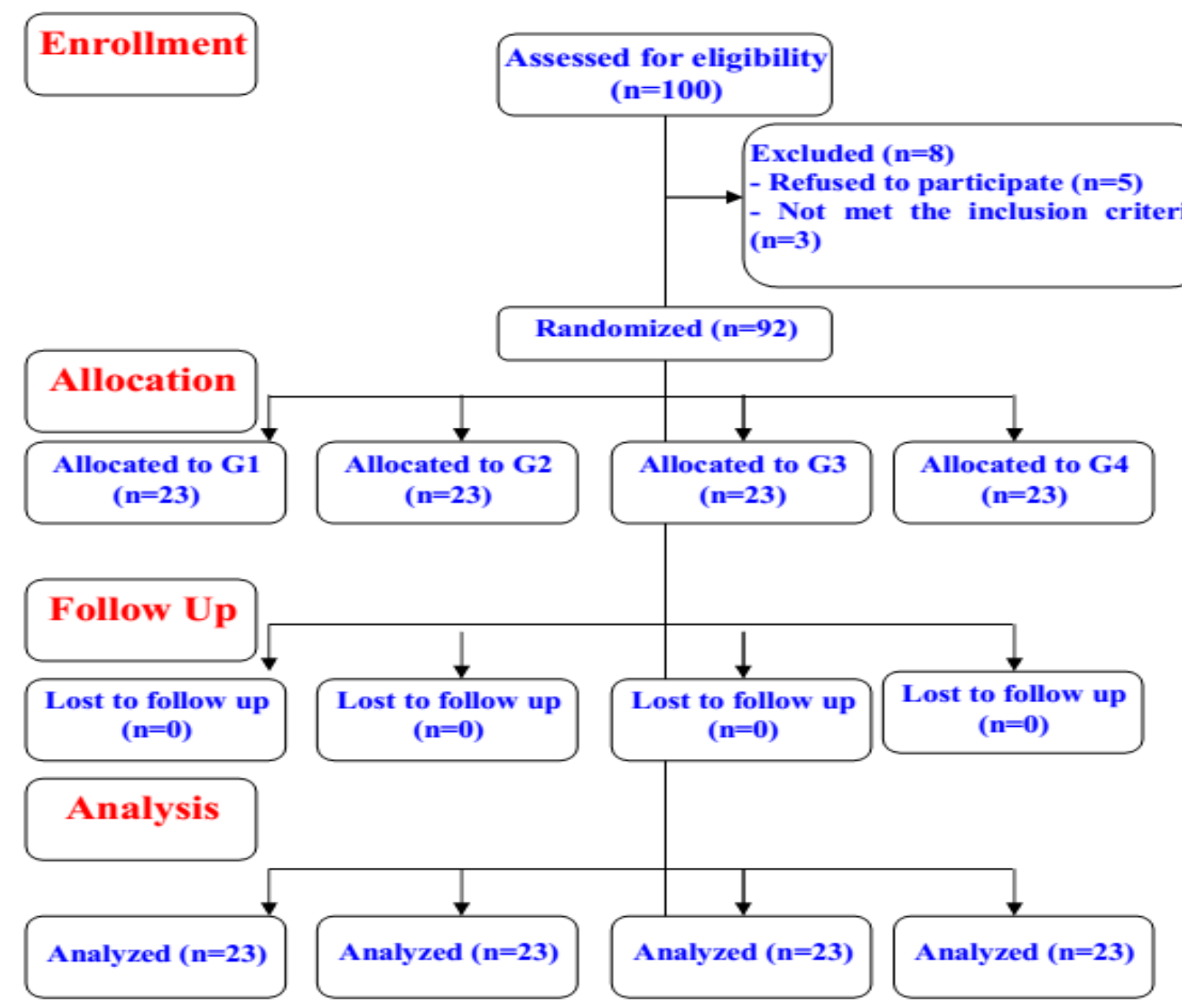

Figure (1): Study Flow Chart

There was no significant difference between the studied groups as regards age or sex. There was no significant difference between the studied groups as regards BMI or duration of surgery (Table 1).

Table (1): Demographic data and baseline characteristics among the studied groups

\begin{tabular}{|c|c|c|c|c|c|c|c|c|c|c|}
\hline Variable & \multicolumn{2}{|c|}{ G1 $(\mathrm{N}=23)$} & \multicolumn{2}{|c|}{ G2(N=23) } & \multicolumn{2}{|c|}{ G3(N=23) } & \multicolumn{2}{|c|}{ G4(N=23) } & $\overline{\mathbf{F}}$ & P value \\
\hline \multicolumn{11}{|l|}{ Age: (Years): } \\
\hline \multirow[t]{2}{*}{$\begin{array}{l}\text { Mean } \pm \text { SD } \\
\text { Range }\end{array}$} & \multicolumn{2}{|c|}{$\begin{array}{c}33.04 \pm 8.16 \\
20-50\end{array}$} & \multicolumn{2}{|c|}{$\begin{array}{c}32.7 \pm 8.69 \\
20-49\end{array}$} & \multicolumn{2}{|c|}{$\begin{array}{c}32.1 \pm 7.59 \\
23-50\end{array}$} & \multicolumn{2}{|c|}{$\begin{array}{c}31.6 \pm 7.01 \\
22-49\end{array}$} & 0.15 & 0.929 \\
\hline & No. & $\%$ & No & $\%$ & No. & $\%$ & No. & $\%$ & $\chi^{2}$ & P value \\
\hline \multicolumn{11}{|l|}{ Sex: } \\
\hline Female & 10 & 43.4 & 11 & 47.8 & 12 & 52.2 & 13 & 56.6 & \multirow{2}{*}{0.86} & \multirow{2}{*}{0.832} \\
\hline Male & 13 & 56.6 & 12 & 52.2 & 11 & 47.8 & 10 & 43.4 & & \\
\hline \multicolumn{11}{|l|}{ BMI $\left(\mathrm{Kg} / \mathrm{m}^{2}\right):$} \\
\hline $\begin{array}{r}\text { Mean } \pm \text { SD } \\
\text { Range }\end{array}$ & \multicolumn{2}{|c|}{$\begin{array}{c}34.01 \pm 2.86 \\
30-40\end{array}$} & \multicolumn{2}{|c|}{$\begin{array}{c}33.1 \pm 2.5 \\
31-40\end{array}$} & \multicolumn{2}{|c|}{$\begin{array}{c}33.1 \pm 1.59 \\
30-39\end{array}$} & \multicolumn{2}{|c|}{$\begin{array}{c}33.5 \pm 1.69 \\
32-38\end{array}$} & 0.86 & 0.462 \\
\hline \multicolumn{11}{|c|}{ Duration of surgery (minutes): } \\
\hline Mean \pm SD & 104 & \pm 22.1 & & \pm 21.5 & 101 & 12.3 & 105. & 1.1 & 0.243 & 0.865 \\
\hline
\end{tabular}

F is for ANOVA test, $\quad \mathrm{P}$ value is significant if $\leq 0.05, \quad$ BMI is for Body Mass Index, $\quad \chi^{2}$ (chi square test)

There was no significant difference regarding heart rate among the studied groups (Table 2). 
Table (2): Heart rate measurements among the studied groups (beat/minute)

\begin{tabular}{|c|c|c|c|c|c|c|}
\hline Variable & $\begin{array}{c}\mathbf{G 1} \\
\mathbf{N}=\mathbf{2 3}\end{array}$ & $\begin{array}{c}\mathbf{G 2} \\
\mathbf{N}=23\end{array}$ & $\begin{array}{c}\text { G3 } \\
\mathbf{N}=23\end{array}$ & $\begin{array}{c}\text { G4 } \\
\mathrm{N}=23\end{array}$ & $\mathbf{F}$ & $P$ value \\
\hline \multicolumn{7}{|l|}{ Tb: } \\
\hline Mean \pm SD & $93.5 \pm 9.3$ & $93.9 \pm 8.5$ & $93.6 \pm 10.7$ & $93.4 \pm 9.1$ & 0.012 & 0.998 \\
\hline \multicolumn{7}{|l|}{ T1: } \\
\hline Mean \pm SD & $84.7 \pm 10.9$ & $91.4 \pm 12.7$ & $87 \pm 13.5$ & $85.6 \pm 10.8$ & 1.4 & 0.247 \\
\hline \multicolumn{7}{|l|}{ T2: } \\
\hline Mean $\pm \mathrm{SD}$ & $80.2 \pm 15.6$ & $84.8 \pm 13.1$ & $82.7 \pm 9.9$ & $89.1 \pm 10.6$ & 2.09 & 0.107 \\
\hline \multicolumn{7}{|l|}{ T3: } \\
\hline Mean \pm SD & $80.8 \pm 13.9$ & $87.4 \pm 14.6$ & $83.4 \pm 15.1$ & $84.2 \pm 14.2$ & 0.813 & 0.489 \\
\hline \multicolumn{7}{|l|}{ T4: } \\
\hline Mean $\pm \mathrm{SD}$ & $72.4 \pm 14.4$ & $77.2 \pm 14.1$ & $81.4 \pm 14.8$ & $75.2 \pm 14.1$ & 1.59 & 0.195 \\
\hline \multicolumn{7}{|l|}{ T5: } \\
\hline Mean \pm SD & $80.5 \pm 12.7$ & $78.6 \pm 12.5$ & $83.5 \pm 11.4$ & $79.2 \pm 12$ & 0.74 & 0.53 \\
\hline \multicolumn{7}{|l|}{ T6: } \\
\hline Mean $\pm \mathrm{SD}$ & $85 \pm 10.7$ & $82.8 \pm 12.3$ & $88.8 \pm 9.6$ & $83.1 \pm 10.1$ & 1.52 & 0.213 \\
\hline \multicolumn{7}{|l|}{ T7: } \\
\hline Mean \pm SD & $91.2 \pm 10$ & $92.5 \pm 11$ & $92 \pm 6.1$ & $91.1 \pm 9.8$ & 0.11 & 0.95 \\
\hline
\end{tabular}

Tb: before induction. T1: immediately after induction of anesthesia.T2; immediately after skin incision.T3: 30 min after skin incision.T4: 1 hour after skin incision.T5: immediately after Post anesthesia Care Unit (PACU) admission T6: 30 min after Post anesthesia Care Unit (PACU) admission.T7: immediatly before discharge. F is for ANOVA test, $\mathrm{p}$ value is significant if $\leq 0.05$

There was no significant difference between the studied groups as regards (MAP) (Table 3).

Table (3): Mean Arterial blood pressure measurements among the studied groups (mmHg)

\begin{tabular}{|c|c|c|c|c|c|c|}
\hline Variable & $\begin{array}{c}\text { G1 } \\
\mathrm{N}=23\end{array}$ & $\begin{array}{c}\mathbf{G} 2 \\
\mathrm{~N}=23\end{array}$ & $\begin{array}{c}\text { G3 } \\
\mathrm{N}=23\end{array}$ & $\begin{array}{c}\text { G4 } \\
\mathrm{N}=23\end{array}$ & $\mathbf{F}$ & $P$ value \\
\hline \multicolumn{7}{|l|}{ Tb: } \\
\hline Mean \pm SD & $86.8 \pm 13.1$ & $84.4 \pm 12.9$ & $83.4 \pm 11.1$ & $82.6 \pm 10.1$ & 0.542 & 0.654 \\
\hline \multicolumn{7}{|l|}{ T1: } \\
\hline Mean \pm SD & $84.5 \pm 12.1$ & $86.8 \pm 15.2$ & $79.6 \pm 10.8$ & $77.4 \pm 12.6$ & 2.63 & 0.054 \\
\hline \multicolumn{7}{|l|}{ T2: } \\
\hline Mean \pm SD & $84 \pm 9.2$ & $84.8 \pm 13.2$ & $84.1 \pm 11.6$ & $82.1 \pm 12.7$ & 0.221 & 0.881 \\
\hline \multicolumn{7}{|l|}{ T3: } \\
\hline Mean \pm SD & $85 \pm 16.8$ & $80.8 \pm 12.1$ & $84.2 \pm 14.1$ & $76.7 \pm 10.9$ & 1.76 & 0.159 \\
\hline \multicolumn{7}{|l|}{ T4: } \\
\hline Mean $\pm \mathrm{SD}$ & $87.5 \pm 16.1$ & $85.3 \pm 11.8$ & $85.2 \pm 12.1$ & $82.4 \pm 13.2$ & 0.55 & 0.643 \\
\hline \multicolumn{7}{|l|}{ T5: } \\
\hline Mean \pm SD & $86.5 \pm 13.9$ & $82.3 \pm 11.2$ & $84.2 \pm 12.4$ & $83.2 \pm 10.3$ & 0.52 & 0.669 \\
\hline \multicolumn{7}{|l|}{ T6: } \\
\hline Mean \pm SD & $84.6 \pm 11.4$ & $83.3 \pm 11.2$ & $82.1 \pm 10.4$ & $81.2 \pm 10.5$ & 0.423 & 0.736 \\
\hline \multicolumn{7}{|l|}{ T7: } \\
\hline Mean $\pm \mathrm{SD}$ & $85.6 \pm 11.6$ & $86.7 \pm 12.5$ & $79.8 \pm 11.8$ & $79.4 \pm 10.8$ & 2.44 & 0.069 \\
\hline
\end{tabular}

MAP is for Mean Arterial blood pressure, $\mathrm{F}$ is for ANOVA test, $\mathrm{p}$ value is significant if $\leq 0.05$, Tb: before induction. T1: immediately after induction of Anesthesia.T2; immediately after skin incision.T3: 30 min after skin incision.T4: 1 hour after skin incision.T5: immediately after Post anesthesia Care Unit (PACU) admission T6: 30 min after Post anesthesia Care Unit (PACU) admission.T7: immediatly before discharge. F is for ANOVA test, $\mathrm{p}$ value is significant if $\leq 0.05$

There was no significant difference between the studied groups at TB, T1, T2 regarding oxygen saturation, but there was a significance difference between G3 and G1 \& G2 at T5, T6 \& T7 as regards oxygen saturation. There was significant difference between the studied groups concerning oxygen saturation as the fourth group had the highest oxygen saturation at T3, T4, T5, T6 \& T7 (Table 4). 
Table (4): Oxygen saturation values of the studied groups (\%)

\begin{tabular}{|c|c|c|c|c|c|c|}
\hline Variable & \begin{tabular}{|l|} 
GROUP 1 \\
$\mathrm{N}=23$
\end{tabular} & \begin{tabular}{|l|} 
GROUP 2 \\
$\mathrm{~N}=23$
\end{tabular} & $\begin{array}{c}\text { GROUP } 3 \\
\mathbf{N}=23\end{array}$ & $\begin{array}{c}\text { GROUP } 4 \\
\mathbf{N}=23\end{array}$ & $\mathbf{F}$ & P value \\
\hline \multicolumn{7}{|l|}{ Tb: } \\
\hline Mean \pm SD & $97.7 \pm 1.5$ & $97.4 \pm 1.6$ & $96.4 \pm 2.3$ & $97.2 \pm 1.9$ & 2.07 & 0.109 \\
\hline \multicolumn{7}{|l|}{ T1: } \\
\hline Mean \pm SD & $97 \pm 1.6$ & $96.9 \pm 1.8$ & $96.7 \pm 2.1$ & $97 \pm 1.4$ & 0.151 & 0.929 \\
\hline \multicolumn{7}{|l|}{ T2: } \\
\hline Mean \pm SD & $96.8 \pm 2.2$ & $96.5 \pm 2.7$ & $97.2 \pm 1.9$ & $97.6 \pm 1.2$ & 1.227 & 0.305 \\
\hline \multicolumn{7}{|l|}{ T3: } \\
\hline Mean \pm SD & $95.2 \pm 2.5$ & $94.4 \pm 2.6$ & $95.8 \pm 2.4$ & $97.2 \pm 1.8$ & 5.838 & $0.001(\mathrm{~S})$ \\
\hline \multicolumn{7}{|l|}{ T4: } \\
\hline Mean \pm SD & $94.5 \pm 3.23$ & $93.8 \pm 3.4$ & $95.6 \pm 2.2$ & $97 \pm 1.7$ & 6.033 & $0.001(\mathrm{~S})$ \\
\hline \multicolumn{7}{|l|}{ T5: } \\
\hline Mean \pm SD & $92.2 \pm 2.7$ & $91.8 \pm 3.7$ & $95.5 \pm 3.1$ & $97.1 \pm 1.5$ & 18.536 & $<0.001(\mathrm{HS})$ \\
\hline \multicolumn{7}{|l|}{ T6: } \\
\hline Mean \pm SD & $90.4 \pm 3.2$ & $90.1 \pm 3.5$ & $95.1 \pm 2.9$ & $97.4 \pm 1.1$ & 36.951 & $<0.001(\mathrm{HS})$ \\
\hline \multicolumn{7}{|l|}{ T7: } \\
\hline Mean \pm SD & $89.4 \pm 3.4$ & $89.1 \pm 3.8$ & $95.2 \pm 2.7$ & $97.5 \pm 1.2$ & 46.887 & $<0.001$ (HS) \\
\hline
\end{tabular}

$\mathrm{F}$ is for ANOVA test, $\mathrm{p}$ value is significant if $\leq 0.05$, TB: before induction. $\mathrm{T} 1$ : immediately after induction of Anesthesia.T2; immediately after skin incision. T3: 30 min after skin incision. T4: 1 hour after skin incision.T5: immediately after PACU admission. T6:30 min after admission to PACU . T7: immediately before discharge There was a significant difference between the studied groups as regards length of stay in PACU as the 4th group had the lowest length of stay in PACU. There was a significant difference between the studied groups regarding postoperative need of $100 \%$ oxygen with the least need in group 4 . There was a significant difference between the studied groups as regards postoperative complications as G4 had the least complications (Table 5).

Table (5): Length of stay in post-anesthesia care unit (PACU) and need for $100 \% \mathrm{FIO}_{2}$ and postoperative complications in the studied groups

\begin{tabular}{|c|c|c|c|c|c|c|c|c|c|c|}
\hline Variable & \multicolumn{2}{|c|}{$\begin{array}{c}\text { GROUP } 1 \\
\mathbf{N}=23\end{array}$} & \multicolumn{2}{|c|}{$\begin{array}{c}\text { GROUP } 2 \\
\mathrm{~N}=23\end{array}$} & \multicolumn{2}{|c|}{$\begin{array}{c}\text { GROUP } 3 \\
\quad \mathbf{N}=23\end{array}$} & \multicolumn{2}{|c|}{$\begin{array}{c}\text { GROUP } 4 \\
\mathbf{N}=23\end{array}$} & $\mathbf{F}$ & $P$ value \\
\hline \multicolumn{11}{|c|}{ Length of stay in PACU (min): } \\
\hline Mean \pm SD & \multicolumn{2}{|c|}{$86.1 \pm 22.86$} & \multicolumn{2}{|c|}{$87.9 \pm 25.3$} & \multicolumn{2}{|c|}{$77.5 \pm 20.3$} & \multicolumn{2}{|c|}{$66.9 \pm 18.6$} & 4.4 & $\begin{array}{c}<0.03 \\
(\mathrm{~S})\end{array}$ \\
\hline & No & $\%$ & No & $\%$ & No & $\%$ & No. & $\%$ & $\chi^{2}$ & P value \\
\hline \multicolumn{11}{|c|}{ Need for $100 \%$ Fio2 in PACU, n $(\%)$ : } \\
\hline $\begin{array}{l}\text { Yes } \\
\text { No }\end{array}$ & $\begin{array}{c}5 \\
18\end{array}$ & $\begin{array}{l}21.7 \\
78.3\end{array}$ & $\begin{array}{c}7 \\
16\end{array}$ & $\begin{array}{l}30.4 \\
69.6\end{array}$ & $\begin{array}{c}3 \\
20\end{array}$ & $\begin{array}{l}13.0 \\
87.0\end{array}$ & $\begin{array}{c}1 \\
22\end{array}$ & $\begin{array}{c}4.3 \\
95.7\end{array}$ & 6.05 & $\begin{array}{l}0.04 \\
(\mathrm{~S})\end{array}$ \\
\hline \multicolumn{11}{|c|}{ Postoperative Complications } \\
\hline $\begin{array}{l}\text { Hypoxemia } \\
\text { Hypercania } \\
\text { Hemodynamic } \\
\text { instability } \\
\text { Pneumothorax }\end{array}$ & $\begin{array}{l}3 \\
2 \\
1 \\
0\end{array}$ & $\begin{array}{c}13.05 \\
8.7 \\
4.35 \\
0.0\end{array}$ & $\begin{array}{l}3 \\
3 \\
2 \\
0\end{array}$ & $\begin{array}{c}13.05 \\
13.05 \\
8.7 \\
0.0\end{array}$ & $\begin{array}{l}1 \\
0 \\
2 \\
0\end{array}$ & $\begin{array}{c}4.3 \\
50 . \\
0 \\
8.7 \\
0.0\end{array}$ & $\begin{array}{l}0 \\
0 \\
0 \\
0\end{array}$ & $\begin{array}{l}0.0 \\
0.0 \\
0.0 \\
0.0\end{array}$ & 5.3 & $\begin{array}{c}<0.036 \\
(\mathrm{~S})\end{array}$ \\
\hline
\end{tabular}

F is for ANOVA test, $\quad \chi 2$ is for Chi square

$\mathrm{p}$ value is significant if $<0.05$ PACU

FIO2

As regards the $\mathrm{PaO}_{2} / \mathrm{FiO}_{2}$ ratio preoperatively, there was no significant difference between the studied groups as it was 332.4 in G1, 330.1 in G2, 332 in G3 and 334.3 in G4. As regards the $\mathrm{PaO}_{2} / \mathrm{FiO}_{2}$ ratio intraoperatively, there was a significant difference between the studied groups as it was 313.6 in G1, 312.3 in G2, 323.7 in G3 and 329.8 in G4. As regards the $\mathrm{PaO}_{2} / \mathrm{FiO}_{2}$ ratio immediately after PACU admission, there was a significant difference between the studied groups as it was 288.7 in G1, 286.7 in G2, 320.4 in G3 and 326.2 in G4. As regards the $\mathrm{PaO}_{2} / \mathrm{FiO}_{2}$ ratio 30 min after PACU admission, there was a significant difference between the studied groups, as it was 283.5 in G1, 281.3 in G2, 319.8 in G3 and 325.7 in G4 (Fig. 2). 


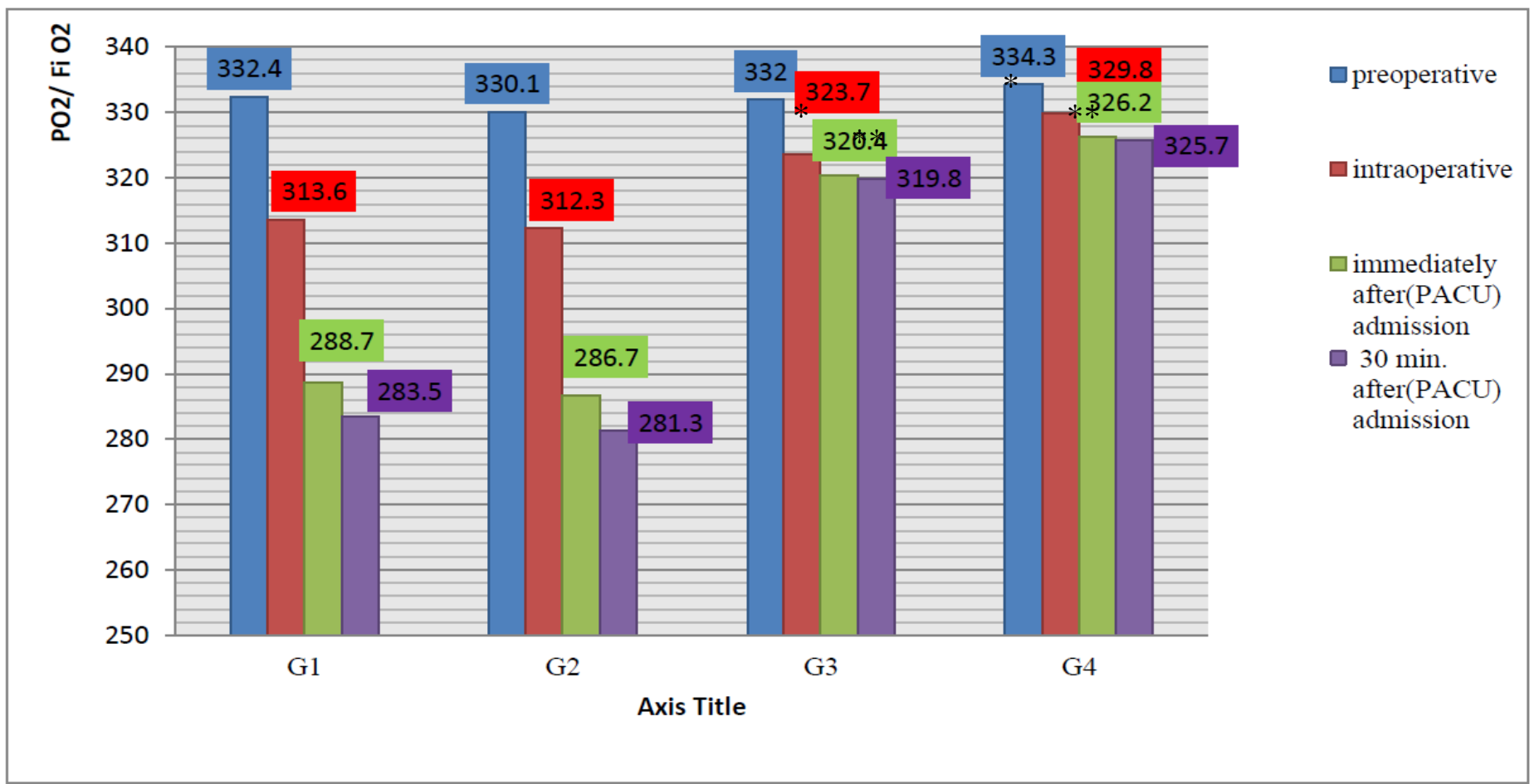

Figure (2): Comparison of $\mathrm{PaO} 2 / \mathrm{FiO} 2$ values between the 4 groups in different times.

$\mathrm{PaO}_{2} / \mathrm{FiO}_{2}$ : arterial partial pressure of oxygen / fraction of inspired oxygen saturation.

* significant difference between the studied groups immediately after PACU admission.

** significant difference between the studied groups 30 minsss after PACU admission.

As regard atelectasis score there was high significant difference between the studied groups as regard lamellar atelectasis as it was 5 in G1, 6 in G2, 3 in G3, 1 in G4. As regard atelectasis score there was a significant difference between the studied groups as regard plate atelectasis as it was 4 in G1, 4 in G2, 2 in G3, 1 in G4. As regard atelectasis score there was a significant difference between the studied groups as regard segmental atelectasis as it was 2 in G1, 3 in G2, 1 in G3, 0 in G4. As regard atelectasis score there was a significant difference between the studied groups as regard labor atelectasis as it was 3 in G1, 4 in G2, 1 in G3, 0 in G4 (Fig. 3).

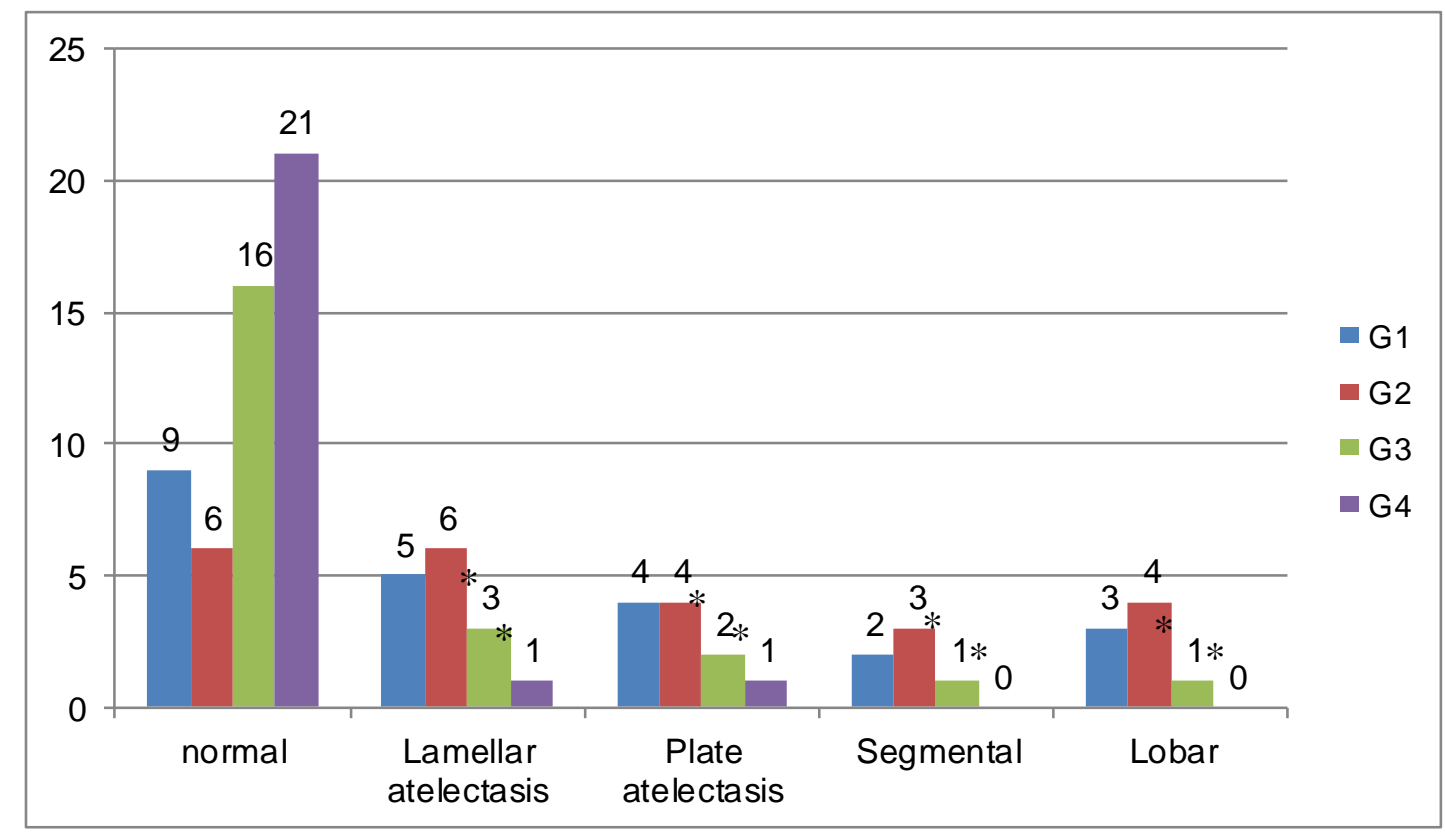

Figure (3): Number of Patients in the 4 Groups According to Their Atelectasis Score

* Significant difference between the studied groups as regards lamellar atelectasis, plate atelectasis, segment atelectasis and labor atelectasis. 


\section{DISCUSSION}

The number of obese patients undergoing surgery is increasing. The pathophysiological changes induced by obesity make these patients prone to peri-operative complications especially pulmonary complications, which are the main cause of overall peri-operative morbidity and mortality following general anesthesia. Reduction of these complications would improve the quality of medical care and decrease hospital stay and costs ${ }^{(9,10)}$. Different strategies have been investigated to re-expand collapsed lung during general anesthesia to optimize oxygenation and to improve respiratory mechanics ${ }^{(11)}$. The positive end expiratory pressure "PEEP" has been shown to counterbalance the diaphragm cranial shift increasing both functional residual capacity and respiratory system elastance ${ }^{(\mathbf{1 2})}$.

The current study demonstrated that there was no significant difference between the studied groups as regards age or sex, BMI and duration of surgery. Also, there was no significant difference between the studied groups as regards heart rate and mean arterial blood pressure. These results are in agreement with the results obtained by many studies on obese patients ${ }^{(11-16)}$.

Concerning oxygen saturation, the current study found that there was no significant difference between the studied groups at TB, T1 and T2, but there was significant difference between G3 and G1 \& G2 at T5, T6, and T7 as regards oxygen saturation. There was significant difference between the studied groups as regards oxygen saturation as the fourth group had the highest oxygen saturation at T3, T4, T5, T6, and T7. Our results are in agreement with the results of El-Kady et al. (10)

The current study revealed that there was high significant difference between the studied groups as regard length of stay in PACU, as the $4^{\text {th }}$ group had the shortest stay in PACU. Our results is consistent with the results of Russel and Graybeal ${ }^{(17)}$ who reported that despite the use of $40 \%$ oxygen given by facemask, $15 \%$ of patients in the PACU will have oxygen saturation 92\% lasting 1 minute. This event seems to prolong the PACU stay and cause more intensive care admissions.

The study showed that there was significant difference between the studied groups as regards need for $100 \% \mathrm{O}_{2}$ in PACU as the $4^{\text {th }}$ groups had the least number of patients need for $100 \% \mathrm{O}_{2}$ in PACU. Our results are consistent with the study of $\mathbf{H u}{ }^{(18)}$ who reported that, recruitment maneuvers followed by positive end expiratory pressure "PEEP" are effective ventilator strategies for obese patients, where there was a statistically significant difference as regards need for $100 \% \mathrm{O}_{2}$ in PACU between the studied groups which is consistent with our for mentioned results.

The current study showed that there was significant difference between the studied groups as regards partial pressure of oxygen $(\mathrm{PaO} 2) /$ fraction inspired oxygen saturation $(\mathrm{FiO} 2)$ values in the intraoperative, immediately postoperative and 30 minutes postoperative, while there was no significant difference between them in the preoperative period. These results are consistent with the results of Souza et al. ${ }^{(19)}$ who compared alveolar recruitment maneuver "RM" versus positive end expiratory pressure "PEEP" to evaluate intraoperative gas exchange, with the mean $\mathrm{PaO}_{2} / \mathrm{FiO}_{2}$ ratio found to be greater in the groups that underwent RM. Also, our results consistent with Elkady et al. ${ }^{(10)}$ stated that regarding the value of $\mathrm{PaO}_{2} / \mathrm{FiO}_{2}$, there was significant difference between them as regards intra-operative and postoperative values as the $4^{\text {th }}$ group has the highest $\mathrm{PaO}_{2} / \mathrm{FiO}_{2}$ ratio.

As regard postoperative pulmonary complications in between the studied groups, there was a significant difference between the studied groups as G4 had the least complications. Xue et al. ${ }^{(20)}$ reported that, in the PACU within $3 \mathrm{~h}$ of surgery, $7 \%$ of patients had at least 1 episode of desaturation $90 \%$ and $3 \%$ desaturated to $85 \%$. This incidence is increased in thoracoabdominal surgery. In the study of Talab et al. (21) illustrated that during the first $48 \mathrm{~h}$ postoperatively, no significant desaturation, chest infection, or bronchospasm were noted in the positive end expiratory pressure "PEEP" $\left(10 \mathrm{cmH}_{2} \mathrm{O}\right)$ group, compared to PEEP $\left(5 \mathrm{cmH}_{2} \mathrm{O}\right)$ and ZEEP (zero-end-expiratory pressure) groups respectively. Talab et al. (21) found that postoperative pulmonary complications occurred only in the ZEEP and "PEEP" $\left(5 \mathrm{~cm} \mathrm{H}_{2} \mathrm{O}\right)$. Our results are in agreement with the results obtained by Talab et al. (21) and Duggan and Kavanagh ${ }^{(22)}$ as postoperative pulmonary complications were present in VC, PC, VC+PEEP groups while not present in VC + PEEP + recruitment maneuver. The same finding was reached with Duggan and Kavanagh ${ }^{(22)}$ who reported that development of atelectasis is associated with decreased lung compliance, impairment of oxygenation, increased pulmonary vascular resistance, and development of lung injury. The adverse effects of atelectasis persist into the postoperative period and can affect patient recovery. There were no pulmonary complications in the group with "PEEP" $10 \mathrm{~cm} \mathrm{H}_{2} \mathrm{O}$.

As regards the number and percentage of patients in the 4 groups according to their atelectasis score. Our study showed that there was significant difference between the studied groups as regards number and percentage of patients in the 4 groups according to their atelectasis score as the $4^{\text {th }}$ group has the highest significant difference. Only two cases in group four developed lamellar and plate atelectasis as was proved by the postoperative CT scan. Our results agree with the study of El Kady et al. ${ }^{(\mathbf{1 0})}$ who demonstrated that pressure control ventilation group showed the highest number of both lobar and segmental atelectasis 
followed by volume control ventilation group, which showed also a high number of segmental atelectasis. Miles ${ }^{(23)}$ reported similar results and concluded that the application of "PEEP" (10 cm H2O) in morbidly obese patients was very effective in preventing atelectasis during the induction of general anesthesia. In the study of Barbosa et al. $^{(24)}$, they performed a meta-analysis and suggested that an open lung approach with "PEEP" in surgical patients improves postoperative oxygenation and decreases postoperative atelectasis without any adverse events. Volume control ventilation "VC" followed by $10 \mathrm{~cm}$ $\mathrm{H} 2 \mathrm{O}$ of Positive End Expiratory Pressure "PEEP" was accompanied by better intraoperative and postoperative oxygenation in addition to a lower atelectasis score in chest CT scan done approximately $2 \mathrm{~h}$ postoperatively in comparison with the $\mathrm{VC}$ alone (25)

The severity and effect of atelectasis are expected to be increased in super morbidly obese patients with a BMI $50 \mathrm{~kg} / \mathrm{m}^{2}$ compared to obese patients with a BMI between 30 and $50 \mathrm{~kg} / \mathrm{m}^{2}$, but the standard CT table cannot support a patient weighing $170 \mathrm{~kg}$, that is why we did not include patients with BMI $50 \mathrm{~kg} / \mathrm{m}^{2}$. We needed to be able to evaluate postoperative atelectasis by CT scan ${ }^{(\mathbf{2 1})}$. Rothen et $_{\text {al }}{ }^{(\mathbf{2 6})}$ found that the vital capacity maneuver "VCM", which is done by sudden increased "PEEP" from $10 \mathrm{~cm} \mathrm{H} 2 \mathrm{O}$ to $40 \mathrm{~cm}$ $\mathrm{H} 2 \mathrm{O}$ for 10 seconds, alone could completely abolish atelectasis that developed after induction of general anesthesia. This can be explained by the difference in patient populations because they applied the VCM to non-obese patients undergoing non-laparoscopic surgery compared to obese patients undergoing nonbariatric abdominal surgeries in our study. The VCM had no deleterious pulmonary effects as measured by extra vascular lung water, pulmonary clearance of 99 mTc-diethylene triamine pentaacetic acid (DTPA), which is a marker of the functional integrity of the alveolo-capillary barrier, and light microscopy in pigs that received repeated VCM hourly for $6 \mathrm{~h}^{(27)}$.

Similarly, in this study, no pneumothorax, air in the mediastinum, or subcutaneous emphysema was detected in chest CT scan done postoperatively in any patient in all groups. Azab et al. ${ }^{(28)}$ concluded that "PEEP" $\left(5 \mathrm{~cm} \mathrm{H}_{2} \mathrm{O}\right)$ prevents deoxygenation during pneumoperitoneum and leads to a lower atelectasis score on CT scan examination up to $2 \mathrm{~h}$ postoperatively. However, their study was carried on non-obese patients, whereas our study was conducted on obese patients with a BMI $30-40 \mathrm{~kg} / \mathrm{m}^{2}$ who had lower functional residual capacity in whom "PEEP" 5 $\mathrm{cm} \mathrm{H} 2 \mathrm{O}$ may not be enough to reopen collapsed alveoli after induction of anesthesia. But the addition of recruitment maneuver to "PEEP" in our study resulted in improvement of oxygenation with lower incidence of atelectasis as the recruitment maneuver increase of the patient's lung volumes and restoration of their pulmonary function to a pre-anesthetic state as long as counterbalancing the diaphragm cranial shift increasing both functional residual capacity and respiratory system elastance.

The limitations of this study were firstly, patients with BMI $>50 \mathrm{~kg} / \mathrm{m}^{2}$ were excluded although the severity and effect of atelectasis were expected to be increased in those patients. But, the standard CT scan table cannot support patients weighing $>170 \mathrm{~kg}$ and we needed to evaluate postoperative atelectasis by CT scan. Secondly, the study time was limited to the early postoperative period only. So, we could not exclude later variation in the measured parameters or later complications. But many other factors may be involved in late pulmonary complications.

\section{CONCLUSION}

Our results suggest that volume control ventilation + "PEEP" + lung recruitment maneuver have beneficial effects on oxygenation applied in the intraoperative period and decrease pulmonary complications in the early post-operative period in obese patients undergoing non-bariatric abdominal surgeries.

Declaration of interest: The authors report no conflicts of interest. The authors alone are responsible for the content and writing of the paper.

Funding information: None declared.

\section{REFERENCES}

1. Candiotti K, Sharma S, Shankar R (2009): Obesity, obstructive sleep apnoea, and diabetes mellitus: anesthetic implications. Br J Anesth., 103 (1): 23-30.

2. Bruells C, Rossaint R (2011): Physiology of gas exchange during anesthesia. Eur J Anesthesiol., 28: 570-9

3. Adams J, Murphy P (2000): Obesity in anesthesia and intensive care. Br J Anesth., 85: 91-108

4. Bamgbade O, Rutter T, Nafiu O (2007): Postoperative complications in obese and nonobese patients. World $\mathrm{J}$ Surg., 31: 556-60.

5. Dority J, Hassan Z, Chau D (2011): Anesthetic Implications of Obesity in the Surgical Patient. Clinics in Colon and Rectal Surgery, 24: 4-8.

6. Sprung J, Whalen F, Comfere T et al. (2009): Alveolar recruitment and arterial desflurane concentration during bariatric surgery. Anesth Analg., 108 (1): 120-127.

7. Frey W, Pilcher J (2003): Obstructive sleep-related breathing disorders in patients evaluated for bariatric surgery. Obes Surg., 13: 676-683

8. King G, Brown N, Diba C (2005): The effects of body weight on airway calibre. Eur Respir J., 25: 896-901.

9. Tianzhu T, Lulong B, Feng C (2014): Effect of protective ventilation on post-operative pulmonary complications in patients undergoing general anesthesia: 
a meta-analysis of randomized controlled trials. $\mathrm{Br} \mathrm{J}$ Aneasth., 4 (6): e005208.

10. El Kady G, Kaschef N, Khalaf K (2018): Comparative Study between Intra-operative Ventilatory Techniques to Prevent Postoperative Pulmonary Complications in Obese Patients Undergoing Laparoscopic Surgery. The Egyptian Journal of Hospital Medicine, 70 (12): $2137-$ 2147.

11. Khalid M, Mohamed M (2011): Peri-operative ventilatory strategies for improving arterial oxygenation and respiratory mechanics in morbidly obese patients undergoing laparoscopic bariatric surgery. Egyptian Journal of Anesthesia, 28: 9-15.

12. Gilda C, Salvatore G, Savino S (2013): Effects of Recruitment Maneuver and Positive End-expiratory Pressure on Respiratory Mechanics and Transpulmonary Pressure during Laparoscopic Surgery. Anesthiology, 118: 114-122.

13. Deborah G, Laura B, Jennifer M (2013): Effectiveness of positive end- expiratory pressure, decreased fraction of inspired oxygen(FIO2) and vital capacity recruitment of pulmonary atelectasis in patients undergoing general anesthesia: a systemic review protocol. JBI Database of Systemic Reviews and Implementation Reports, 11: 9-16.

14.Park C, Jo Y, Kim J (2016): The effect of ventilation strategy on arterial and cerebral oxygenation during laparoscopic bariatric surgery. Obes Surg., 26: 339-344.

15. Emmanuel F, Paolo $P$, Gerald C (2010): Intraoperative Recruitment Maneuver Reverses Detrimental Pneumo-peritoneum- induced Respiratory Effects in Healthy Weight and Obese Patients Undergoing Laparoscopy. Anesthesiology, 113: 13101319.

16. Remistico P, Araujo S, Figueiredo L et al. (2011): Impact of alveolar recruitment maneuver in the postoperative period of video laparoscopic bariatric surgery. Rev Bras Anestesiol., 61 (2): 163-76.

17. Russell G, Graybeal J (1993). Hypoxemic episodes of patients in a postanesthesia care unit. Chest, 104: 899 903

18. Hu X (2016): Effective Ventilation Strategies for Obese Patients Undergoing non-Bariatric Surgery: A Literature Review. AANA J., 84 (1): 35-45.
19.Souza A, Buschpigel M, Mathias L et al. (2009): Analysis of the effected of the alveolar recruitment maneuver on blood oxygenation during bariatric surgery. Rev Bras Anestesiol., 59 (2): 177-86.

20.Xue F, Li B, Zhang G et al. (1999): The influence of surgical sites on early postoperative hypoxemia in adults undergoing elective surgery. Anesth Analg., 88: 213-4

21. Talab H, Zabani I, Abdelrahman H (2009): Intraoperative ventilatory strategies for prevention of pulmonary atelectasis in obese patients undergoing laparoscopic bariatric surgery. Anesth Analg., 109: 1511-6.

22.Duggan M, Kavanagh B (2005): Pulmonary Atelectasis: A Pathogenic Perioperative Entity. Anesthesiology, 102: 838-854.

23. Miles R (2018): Alveolar Recruitment Maneuvers and Noninvasive Positive Pressure Ventilation in Obese Patients: A Quality Improvement Project. Doctoral Projects, $\quad 90$ : 1-40. https://aquila.usm.edu/cgi/viewcontent.cgi?article=1111 \&context=dnp_capstone

24. Barbosa F, Castro A, de Sousa-Rodrigues C (2014): Positive end-expiratory pressure (Positive End Expiratory Pressure "PEEP") during anesthesia for prevention of mortality and postoperative pulmonary complications. Cochrane Database Syst Rev., 6: 792228.

25. Coussa M, Proietti S, Schnyder P et al. (2004): Prevention of atelectasis formation during the induction of general anesthesia in morbidly obese patients. Anesth Analg., 98: 1491-5.

26. Rothen H, Sporre B, Englberg G et al. (1993). Reexpansion of atelectasis during general anesthesia: a computed tomography study. Br J Anesth., 71: 788 -95.

27. Magnusson $\mathrm{L}$, Tenling A, Lemoine $\mathrm{R}$ et al. (2000): The safety of one, or repeated, vital capacity maneuvers during general anesthesia. Anesth Analg., 91: 702-7.

28. Azab T, El-Masry A, Salah M (2005): Effects of intraoperative use of positive end expiratory pressure on lung atelectasis during laparoscopic cholecystectomy. Egyptian J Anesthesia, 21: 219-25. 